\title{
Ultrasound guided chest compressions during cardiopulmonary resuscitation
}

\author{
P Benato, M Zanatta*, V Cianci \\ From 10th WINFOCUS World Congress on Ultrasound in Emergency and Critical Care \\ Kuala Lumpur, Malaysia. 16-19 November 2014
}

\section{Background}

Early and effective chest compressions have a well known pivot role in cardiopulmunary resuscitation (CPR) and 2010 International Consensus on Cardiopulmonary Resuscitation have strongly reinforced its importance.

The efficacy of chest compressions depends on hands position and on compression technique.

Medical education can improve chest compression technique, while the choice of thoracic landmark is always blind even if 2010 consensus indicated that it is reasonable to place the hands in the lower half of the sternum.

\section{Objective}

Critical care ultrasound (CCUS) has changed the approach of critical ill patient and can identify potential reversible causes of cardiac arrest during CPR.

Our challenge is to use CCUS to locate the most appropriate site for chest compressions.

\section{Matherial and method}

We planned a pilot study (in progress) to evaluate the capability of CCUS to improve the quality of chest compressions while CPR is taking place.

\section{Results}

We describe data of a small case series from 6 non traumatic cardiac arrests who was treated both in-hospital and in pre-hospital settings.

In 3 out of 6 patients compressions were correctly performed while in the other 3 cases partials left ventricle compression or the narrowing of the base of the heart and aorta was observed. Ultrasound guided changes in hands position improved passive left ventricle contractility in the 3 incorrect CPR.

\section{Conclusions}

Our study doesn't permit to estimate if the changes made in hands position would have affected the outcome of CPR.

Anyway we think that the possibility to focus the power of the hands over the real position of left ventricle certainly improves the quality of our chest compressions.

\section{Published: 9 March 2015}

\section{References}

1. Sayre MR, Koster RW, Sayre MR, et al: Adult Basic Life Support: 2010 International Consensus on Cardiopulmonary Resuscitation and Emergency Cardiovascular Care Science With Treatment Recommendations. Circulation 2010, 122:S298-S324.

2. Hwang SO, Zhao PG, Choi HJ, et al: Compression of the Left Ventricular Outflow Tract During Cardiopulmonary Resuscitation. Acad Emerg Med 2009, 16:928-933.

3. Shin J, Rhee JE, Kim K: Is the inter-nipple line the correct hand position for effective chest compression in adult cardiopulmonary resuscitation? Resuscitation 2007, 75:305-310.

4. Hoppmann RA, Bell FE, Hoppmann NA, et al: Hand-held ultrasonography to assess external chest compressions on a fresh cadaver. Resuscitation 2013, 84(8):e93.

\section{doi:10.1186/2036-7902-7-S1-A32}

Cite this article as: Benato et al:: Ultrasound guided chest compressions during cardiopulmonary resuscitation. Critical Ultrasound Journal 20157 (Suppl 1):A32.

\footnotetext{
* Correspondence: mirko.zanatta@ulss5.it

Emergency Department of Arzignano Hospital, ULSS5 Ovest Vicentino, Vicenza, Italy
}

\section{SpringerOpen ${ }^{\circ}$}

(c) 2015 Benato; licensee Springer. This is an Open Access article distributed under the terms of the Creative Commons Attribution License (http://creativecommons.org/licenses/by/4.0), which permits unrestricted use, distribution, and reproduction in any medium, provided the original work is properly cited. 